\title{
Kesterite Solar Cells
}

\author{
Vanira Trifiletti* \\ School of Engineering and Materials Science (SEMS), Queen Mary University of London, UK
}

*Corresponding author: Vanira Trifiletti, School of Engineering and Materials Science (SEMS), Queen Mary University of London, Mile End Road, London E1 4NS, UK.
Received Date: August 19, 2019

Published Date: August 26, 2019

\begin{abstract}
The research on photovoltaics is focusing on developing solutions that involve the employment of abundant and non-toxic raw materials, along with simple production processes. Among the light-absorbing materials, which use earth abundant elements and are easily processable, there is the class of kesterite compounds. The efficiency record has been stopped at $12.6 \%$ for five years, but the research is fervent and dedicated to solving the limitations that make the device immature for the commercial market. The involvement and collaboration of researchers from multiple disciplinary areas are feeding the knowledge of this class of materials, promoting it as a possible next leader of the photovoltaic market.
\end{abstract}

\section{Introduction}

For a more sustainable future, technology must evolve by developing solutions that use abundant and non-toxic raw materials, along with simple production processes. In this context, photovoltaic devices based on earth-abundant and low toxic elements can play an important role [1,2]. Among the most promising materials there is the kesterite class, that belongs to the chalcogenide family. The most famous relative is $\mathrm{Cu}(\mathrm{In}, \mathrm{Ga}) \mathrm{Se}_{2}$ alloy, called CIGS, which is usually fabricated by vacuum processes followed by sintering in Selenide atmosphere, and rare elements are involved. Therefore, even if CIGS reach high performances, [3] its cost remains too high. By replacing two indium $\left(\mathrm{In}^{+3}\right)$ or gallium $\left(\mathrm{Ga}^{+3}\right)$ with one tin $\left(\mathrm{Sn}^{+4}\right)$ and one zinc $\left(\mathrm{Zn}^{+2}\right)$, Kesterite-based photovoltaics using $\mathrm{Cu}_{2} \mathrm{ZnSnS}_{4}$ (CZTS), $\mathrm{Cu}_{2} \mathrm{ZnSnSe}_{4}$ (CZTSe) and $\mathrm{Cu}_{2} \mathrm{ZnSn}(\mathrm{S}, \mathrm{Se})_{4}$ (CZTSSe) is emerging as the most viable alternative [4]. Kesterite-based solar cells express lower performance than CIGS, but it is composed of abundant and low toxic elements. In Nature, it is a mineral where zinc and iron share the same lattice sites. In the laboratory, it can be synthesized as a p- type semiconductor material, and lately, it is attracting increasing attention, with the aim of decreasing the thinfilm photovoltaics production cost and lowering the environmental impact [5]. Kesterite has a high absorption coefficient, about $10^{5} \mathrm{~cm}^{-}$ ${ }^{1}$, and a direct band interval in the range from 1.0 to $1.5 \mathrm{eV}$, allowing a useful collection of incident photons by a layer thicknesses of a few microns [6]. As Photo-absorber, kesterite displays an optimal direct bandgap and a high absorption coefficient. Moreover, the energy band gap can be tuned for total or partial replacement of the components. Therefore, with less toxic and more abundant elements, with optimal band levels and high absorption coefficients, kesterite compounds are promising candidates for application in solar cells. The conventional methodology to produce kesteritebased solar cells is based on the co-evaporation of single metal elements or the sputtering of the appropriate metallic precursors, followed by a crystallization at high temperature in the presence of Se and/or S vapor [7]. At the same time, an intense research is developed on vacuum-free deposition methods, which can be summarized in three main categories:

1. deposition of solutions based on electrochemical techniques [7];

2. printing/coating from precursor solutions [7];

3. printing/coating from particle-based solutions [7].

The first kesterite solar cell was built with vacuum techniques by Katagiri et al. [8], showing a conversion efficiency of $0.66 \%$ in 1997 [8]; the current $12.6 \%$ record efficiency belonged to CZTSSe and was reported in 2014 [9]. Surprisingly, most of the record devices since 2009 have been made using a solution process for depositing the absorber film, contradicting the paradigm that the films deposited by wet chemistry generally generate lower performances compared to the similar ones deposited in vacuum [10]. Moreover, the non-vacuum technologies have the advantages of lowering the production costs and giving high uniformity of the final stoichiometry composition [5]. 
However, further improvements are needed for achieving the efficiency required for the practical application: secondary phases have not been sufficiently reduced; the relationship between the growth process and the chemical composition is not entirely focused, the transport properties and the recombination of photo generated carriers' phenomena are not yet fully described. Moreover, the device architecture commonly employed is the same one used for CIGS, although it is not optimized for the kesterite. This mini review describes how many efforts are being made to fill these gaps and how much room for improvement this class of materials owns.

\section{Defects and Doping}

It is well known that to obtain high-efficiency devices, it is necessary to obtain an off-stoichiometric composition [8]. It is required that the material be copper-poor and rich in zinc $[5,11]$. The kesterite structure can adapt to both copper-poor and copperrich compositions, without changing the structure, except in terms of cation distribution [12]. During the kesterite synthesis, the first species that is formed is $\mathrm{ZnX}$ (with $\mathrm{X}=\mathrm{S}$ and/or Se), followed by the formation of the other binary or ternary compounds, so the structure is poor in Zinc at the beginning of its formation. Therefore, to compensate for this deficit, zinc-rich reaction conditions are needed [13]. The main point defects are $\mathrm{V}_{\mathrm{Cu}^{\prime}} \mathrm{Cu}_{\mathrm{Zn}}$ (acceptors) and $\mathrm{Zn}_{\mathrm{Cu}}$ (donor) [13]. Since high-efficiency devices are poor in $\mathrm{Cu}, \mathrm{V}_{\mathrm{Cu}}$ plays a fundamental role in intrinsic doping. Furthermore, even in CIGS, [14] p-doping is also explained by the presence of $\mathrm{V}_{\mathrm{Cu}}$. A final consideration to account is related to the volatility of Snchalcogenide species and the resulting possible decomposition of kesterite at relatively high temperatures [15]. After the sintering, during the cool-down process, it is highly possible that kesterite release $\mathrm{Sn}$ to the atmosphere [16], leading to an Sn-loss from the surface, creating Sn-poor conditions and the associated defects. In addition, the kesterite structure is reach of intrinsic deep defects, which can be compensated through proper design of the extrinsic doping. The types of extrinsic doping can be classified as:

1. with isoelectronic elements of the same family of $\mathrm{Cu}, \mathrm{Zn}$ and $\mathrm{Sn}$, i.e. Ag, Cd, and Ge [17];

2. with alkaline elements, such as $\mathrm{Li}, \mathrm{Na}, \mathrm{K}, \mathrm{Rb}$, and $\mathrm{Cs}$ [17];

3. with unconventional elements such as $\mathrm{In}, \mathrm{Bi}, \mathrm{Sb}$, and $\mathrm{Fe}$ [17].

Some remarkable results have been obtained using small amounts of $\mathrm{Ge}$, attributing the beneficial effect to the reduced loss of $\mathrm{Sn}$ (with a relative minimization of the secondary phases), to the reduction of deep defects, and the downgrading of recombination to the grains' boundaries [18]. Also, $\mathrm{Na}$ is related to the increase in the grain size in concentration of charge carriers [19-21]. This phenomenon can be explained either by hypothesizing the passivation of $\mathrm{Zn}_{\mathrm{Cu}}$ donor defects [22], or by the Na diffusion to the grain boundaries during the cooling process, thus generating more $\mathrm{V}_{\mathrm{Cu}}$ in bulk [17].

\section{Interfaces and Device Architecture}

Another key issue is related to the poor quality of the interfaces. It can be improved by adequately choosing the other layers that compose the device (Figure 1).

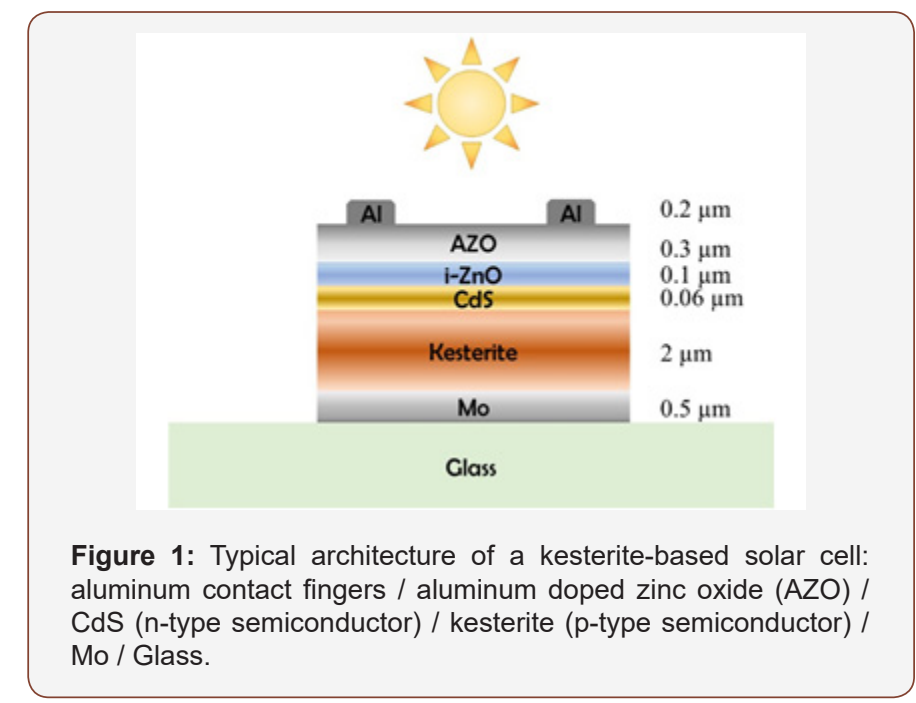

A chalcogenide-based solar cell consists of a series of layers of different materials, as shown in (Figure 1). The two electrodes are the Mo, deposited on a glass plate that acts as a charge extractor for the holes, and the aluminium doped zinc oxide (AZO), which is instead used to collect the electrons. The kesterite is a p-type semiconductor, therefore a layer of cadmium sulphide, CdS, n-type semiconductor, is chemically deposited to form the p-n junction. Since the layer of the absorber material could be irregular, and the CdS layer is extremely thin, an intrinsic $\mathrm{ZnO}$ layer, i-ZnO, is deposited above the CdS to prevent the two electrodes (Mo and AZO) coming into contact, so putting the cell in short circuit. Above the $\mathrm{AZO}$ thin strips of $\mathrm{Al}$ or $\mathrm{Ag} / \mathrm{Al}$ alloys are deposited which collect the current produced. Mo, $\mathrm{ZnO}$ and $\mathrm{AZO}$ are deposited by cathodic sputtering, while the aluminum contacts are made using a thermal evaporator $[4,10]$. Many of the defects at the interface between kesterite and adjacent materials are created during the annealing process, due to the inter-diffusion of the components. Secondary phases can, therefore, be had, such as $\mathrm{Cu}_{2} \mathrm{~S}$ near the $\mathrm{CdS}$ and $\mathrm{ZnS}$ / $\mathrm{SnS}_{2}$ close to Mo, thus destroying the bands' alignment [23-25]. Until now, the CdS is the most efficient buffer layer for kesterite based solar cells and CIGS, but there is a strong demand for the development of a Cd-free buffer layer, due to the toxicity of the $\mathrm{Cd}$ and its concerns regarding the long-term safety. Furthermore, the alignment of the band between the kesterite and CdS is not ideal, increasing recombination at the interface. [4] Some interesting works report an improvement in performance, due to a decrease in recombination and to a more effective charge collection, using $\mathrm{Zn}$-based buffers such as $\mathrm{Zn}_{1-\mathrm{x}} \mathrm{Sn}_{\mathrm{x}} \mathrm{O}_{\mathrm{y}}$ [26], $\mathrm{Zn}(0, \mathrm{~S})$ (which varying the sulphur-oxygen ratio tunes the offset of the conduction band) [27], or simply ZnS [28]. Moreover, during the sulfurization process that is commonly applied during sintering, a $\mathrm{MoS}_{2}$ or $\mathrm{MoSe}_{2}$ layer is generated between CZTS and Mo, which depending on the thickness can completely inhibit the extraction of the charge [29-31]. Mo 
is used because it is well known and applied in high-efficiency solar cells like CIS, CIGS [32], but alternatives are being sought for kesterite, such as W, ITO, FTO, Cr, V, Ti, Mn, Au, Ni, Ag, Pt, Nb, leading to some encouraging results $[5,33]$. Another way to overcome the drawbacks of the Mo use is to insert an intermediate nanometres size layer between $\mathrm{Mo}$ and CZTS, such as $\mathrm{TiN}, \mathrm{Ag}, \mathrm{Bi}, \mathrm{C}, \mathrm{ZnO}, \mathrm{Al}_{2} \mathrm{O}_{3}$, $\mathrm{TiB}_{2}[5,33]$.

\section{Conclusion}

Although the efficiency record has not improved over the last five years, the basic understanding and the development of specific synthesis methods for this class of compounds have made significant steps forward, involving more and more research groups. Being able to make high-efficiency devices using low-cost methodologies is a great challenge for the whole scientific community. The main reason for the low efficiency of the solar cell in kesterite is the high loss of charge carriers due to recombination. Therefore, the defects must be managed to reduce the recombination processes and increase the charge collection. Several processes have been tested, but still, the presence of deleterious secondary phases have not yet been sufficiently reduced. Moreover, the architecture of the device used up to now is not optimised for kesterite; more work is needed to reinvent an architecture dedicated to kesterite. However, considering that more and more researchers from the chemical, physical and engineering areas are combining their efforts to bring the efficiencies of these solar cells to competitive values, this class of materials can effectively become the next leader in the photovoltaic market.

\section{Acknowledgment}

None.

\section{Conflict of Interest}

No conflict of interest.

\section{References}

1. Le Donne A, Trifiletti V, Binetti S (2019) New Earth-Abundant Thin Film Solar Cells Based on Chalcogenides. Front Chem 7: 297.

2. Polman A, Knight M, Garnett EC, Ehrler B, Sinke WC (2016) Photovoltaic materials: Present efficiencies and future challenges. Science 352(6283): aad4424.

3. Ramanujam J, and Singh UP (2017) Copper indium gallium selenide based solar cells - a review. Energy Environ Sci 10: 1306-1319.

4. Liu X, Feng Y, Cui H, Liu F, Hao X, et al. (2016) The current status and future prospects of kesterite solar cells: a brief review. Prog Photovolt Res Appl 24(6): 879-898.

5. Ito K (2015) Copper zinc tin sulphide-based thin film solar cells. Electronic Materials John, Wiley \& Sons, Ltd.

6. Mitzi DB, Gunawan O, Todorov TK, Wang K, Guha S (2011) The path towards a high-performance solution-processed kesterite solar cell. Solar Energy Materials and Solar Cells 95(6): 1421-1436.

7. Azimi H, Hou Y, Brabec CJ (2014) Towards low-cost, environmentally friendly printed chalcopyrite and kesterite solar cells. Energy \& Environmental Science 7: 1829-1849.

8. Katagiri H, Sasaguchi N, Hando S, Hoshino S, Ohashi], et al. (1997) Preparation and evaluation of $\mathrm{Cu}_{2} \mathrm{ZnSnS}_{4}$ thin films by sulfurization of
EB evaporated precursors. Solar Energy Materials and Solar Cells 49(14): 407-414

9. Wang W, Winkler MT, Gunawan O, Gokmen T, Todorov TK, et al. (2014) Device Characteristics of CZTSSe Thin-Film Solar Cells with 12.6\% Efficiency. Adv Energy Mater 4(7): 1301465

10. Paire M, Delbos S, Vidal J, Naghavi N, Guillemoles JF (2014) Chalcogenide Thin-Film Solar Cells. In Solar Cell Materials pp 145-215, John Wiley \& Sons, Ltd.

11. Delbos S (2012) Kësterite thin films for photovoltaics: a review. EPJ Photovolt 3: 35004

12. Valle Rios LE, Neldner K, Gurieva G, Schorr S (2016) Existence of offstoichiometric single phase kesterite. Journal of Alloys and Compounds 657(5): 408-413.

13. Chen S, Yang JH, Gong XG, Walsh A, Wei SH (2010) Intrinsic point defects and complexes in the quaternary kesterite semiconductor $\mathrm{Cu}_{2} \mathrm{ZnSnS}_{4}$. Physical Review B 81(24): 245204.

14. Nishimura T, Sugiura H, Nakada K, Yamada A (2018) Characterization of Interface Between Accurately Controlled $\mathrm{Cu}$-Deficient Layer and $\mathrm{Cu}$ (In,Ga)Se ${ }_{2}$ Absorber for $\mathrm{Cu}(\mathrm{In}, \mathrm{Ga}) \mathrm{Se}_{2}$ Solar Cells (Phys. Status Solidi RRL 8/2018), physica status solidi (RRL). Rapid Research Letters 12(8): 1870327.

15. Redinger A, Berg DM, Dale PJ, Siebentritt S (2011) The Consequences of Kesterite 4 Equilibria for Efficient Solar Cells. J Am Chem Soc133(10): 3320-3323.

16. Xie H, Sánchez Y, López-Marino S, Espíndola-Rodríguez M, Neuschitzer M, et al. (2014) Impact of Sn(S,Se) Secondary Phases in Cu2ZnSn(S,Se) 4 Solar Cells: a Chemical Route for Their Selective Removal and Absorber Surface Passivation, ACS Applied Materials \& Interfaces 6(15): 1274412751.

17. Giraldo S, Jehl Z, Placidi M, Izquierdo-Roca V, Pérez-Rodríguez A, et al. (2019) Progress and Perspectives of Thin Film Kesterite Photovoltaic Technology: A Critical Review. Advanced Materials 31(6): 1806692.

18. Neuschitzer M, Rodriguez ME, Guc M, Marquez JA, Giraldo S, et al. (2018) Revealing the beneficial effects of Ge doping on $\mathrm{Cu}_{2} \mathrm{ZnSnSe}$ thin film solar cells. Journal of Materials Chemistry A 6(25): 11759-11772.

19. Xie H, López-Marino S, Olar T, Sánchez Y, Neuschitzer M, et al. (2016) Impact of Na Dynamics at the Cu2ZnSn(S,Se)4/CdS Interface During Post Low Temperature Treatment of Absorbers. ACS Applied Materials \& Interfaces 8(7): 5017-5024.

20. Haass SG, Andres C, Figi R, Schreiner C, Bürki M, et al. (2018) Complex Interplay between Absorber Composition and Alkali Doping in HighEfficiency Kesterite Solar Cells. Advanced Energy Materials 8(4): 1701760.

21. Andres C, Schwarz T, Haass SG, Weiss TP, Carron R, et al. (2018) Decoupling of optoelectronic properties from morphological changes in sodium treated kesterite thin film solar cells. Solar Energy 175(15): 94-100.

22. Gurieva G, Rios LEV, Franz A, Whitfield P, Schorr S (2018) Intrinsic point defects in off-stoichiometric Cu2ZnSnSe4: A neutron diffraction study. Journal of Applied Physics 123(16): 161519.

23. Wätjen JT, Scragg JJ, Ericson T, Edoff M, Platzer-Björkman C (2013) Secondary compound formation revealed by transmission electron microscopy at the $\mathrm{Cu}_{2} \mathrm{ZnSnS}_{4} /$ Mo interface. Thin Solid Films 535(15): 31-34.

24. Muhunthan N, Singh OP, Thakur MK, Karthikeyan P, Singh D, et al. (2014) Interfacial Properties of CZTS Thin Film Solar Cell. Journal of Solar Energy 8.

25. Hao X (2018) Heterojunction Interface Engineering for $>10 \%$ Efficient Earth-abundant and Environmental-friendly Pure Sulfide Kesterite Solar Cells. The International Photonics and Optoelectronics Meeting (POEM), p PT3B 4, Optical Society of America, Wuhan.

26. Platzer-Björkman C, Frisk C, Larsen JK, Ericson T, Li SY, et al. (2015) Reduced interface recombination in $\mathrm{Cu} 2 \mathrm{ZnSnS4}$ solar cells with atomic 
layer deposition Zn1-xSnxOy buffer layers. Applied Physics Letters 107(24): 243904.

27. Ericson T, Scragg JJ, Hultqvist A, Wätjen JT, Szaniawski P, et al. (2014) Zn $(0, S)$ Buffer Layers and Thickness Variations of CdS Buffer for $\mathrm{Cu}_{2} \mathrm{ZnSnS}_{4}$ Solar Cells. IEEE Journal of Photovoltaics 4(1): 465-469.

28. Nguyen M, Ernits K, Tai KF, Ng CF, Pramana SS, et al. (2015) ZnS buffer layer for $\mathrm{Cu}_{2} \mathrm{ZnSn}(\mathrm{SSe})_{4}$ monograin layer solar cell. Solar Energy 111: 344-349.

29. Shin B, Zhu Y, Bojarczuk NA, Chey SJ, Guha S (2012) Control of an interfacial MoSe2 layer in Cu2ZnSnSe4 thin film solar cells: 8.9\% power conversion efficiency with a TiN diffusion barrier. Applied Physics Letters 101(5): 053903.
30.Scragg JJ., Kubart T, Wätjen JT, Ericson T, Linnarsson MK, PlatzerBjörkman C (2013) Effects of Back Contact Instability on $\mathrm{Cu}_{2} \mathrm{ZnSnS}_{4}$ Devices and Processes. Chemistry of Materials 25: 3162-3171.

31. Yang KJ, Sim JH, Jeon B, Son DH, Kim DH, et al. (2015) Effects of Na and $\mathrm{MoS}_{2}$ on $\mathrm{Cu}_{2} \mathrm{ZnSnS}_{4}$ thin-film solar cell, Progress in Photovoltaics: Research and Applications 23(7): 862-873.

32. Assmann L, Bernède JC, Drici A, Amory C, Halgand E, et al. (2005) Study of the Mo thin films and Mo/CIGS interface properties. Applied Surface Science 246(1-3): 159-166.

33. Pal K, Singh P, Bhaduri A, Thapa KB (2019) Current challenges and future prospects for a highly efficient ( $>20 \%$ ) kesterite CZTS solar cell: A review. Solar Energy Materials and Solar Cells 196: 138-156. 